\title{
NUTRIÇÃO COM BORO NA SOJA EM FUNÇÃO DA DISPONIBILIDADE DE ÁGUA NO SOLO
}

\author{
Nutrition with boron in soybean as function of soil water availability
}

\author{
Renan Cesar Dias da Silva ${ }^{1 *}$; Geovani Soares da Silva Junior ${ }^{2}$; Camila dos Santos Silva ${ }^{3}$; Caroline Teodoro dos \\ Santos ${ }^{4}$; Adilson Pelá ${ }^{5}$ \\ ${ }^{1}$ Mestre em Produção Vegetal; Universidade Estadual de Goiás, Câmpus Ipameri, Ipameri-GO; e-mail \\ renancesar.agro@outlook.com \\ *Autor para correspondência \\ 2Bacharel em Agronomia; Universidade Estadual de Goiás; giovaniiagro@outlook.com \\ ${ }^{3}$ Graduando em Agronomia; Universidade Estadual de Goiás; silvaa.cs@outlook.com \\ ${ }^{4}$ Graduando em Agronomia; Universidade Estadual de Goiás; teodorocaroline@gmail.com \\ 5Prof. Dr., programa de Pós-Graduação em Produção Vegetal, Universidade Estadual de Goiás, Campus Ipameri.
}

Artigo enviado em 25/05/2017, aceito em 02/09/2017 e publicado em 20/12/2017.

Resumo - A adubação com boro geralmente é aplicada sem orientação adequada, usando sempre a filosofia de segurança, podendo acarretar problemas de nutrição nas plantas. O objetivo do trabalho foi avaliar os efeitos da aplicação de boro e capacidade de retenção de água no solo, nos componentes de produção, na produtividade e no acúmulo de boro na soja. Realizou-se um experimento em Ipameri-GO. O delineamento foi inteiramente casualizados (DIC) no esquema fatorial 3 x 5, sendo o primeiro fator disponibilidade de água (50; 70 e $90 \%$ da capacidade máxima de retenção de água no solo - CRA), e o segundo as doses de boro $\left(0 ; 0,5 ; 1,0 ; 1,5\right.$ e $\left.2,0 \mathrm{mg} \mathrm{dm}^{-3}\right)$, com 4 repetições, em vasos de $5 \mathrm{dm}^{3}$ de solo. Foram analisados o número de vagens/planta, número de grãos/vagem, massa seca da parte aérea e raiz, acúmulo de boro na parte aérea, raiz e acúmulo total de boro, a massa seca de 100 grãos e a produtividade por planta. Os resultados foram submetidos à análise de variância e de regressão. Verificou-se interação entre doses de boro e CRA. Com a CRA de $50 \%$ as plantas não respondem a adubação boratada. Com a disponibilidade de água de 70\% da CRA, o acúmulo de boro é crescente com as doses, mas a massa seca de raiz e de parte aérea, o número de vagens por planta e a produtividade de grãos aumentam até as doses estimadas de 0,7 a 1,0 $\mathrm{mg} \mathrm{dm}^{-3}$. Quando a disponibilidade de água no solo é alta (CRA 90\%), a massa seca de parte aérea e raiz, o acúmulo de boro na planta e número de vagens por planta aumenta até a dose máxima testada.

Palavras-chave-Glycine max L., micronutriente, adubação

Abstract - Boron fertilization is applied without adequate support, using a safety philosophy, which can lead to nutritional problems in plants. The objective of this work was to evaluate the effects of boron application and water retention capacity on soil components on yield, productivity and boron accumulation in soybean. An experiment was carried out in Ipameri-GO. The experimental design was completely randomized (DIC) in the factorial scheme $3 \times 5$. The first factor was the availability of water (50,70 and $90 \%$ of the maximum soil water retention capacity - SWRC. The second factor consisted of boron $\left(0 ; 0,5 ; 1,0 ; 1,5\right.$ e 2,0 $\left.\mathrm{mg} \mathrm{dm}^{-3}\right)$ with four replication, in pots containing $5 \mathrm{dm}^{3}$ of soil. Were analyzed the number of pods / plant, number of grains / pod, shoot dry mass and root, accumulation of boron in shoot, root and total accumulation of boron, dry mass of 100 grains and productivity per plant. The results were submitted to analysis of variance and regression. There was interaction between doses of boron and SWRC. With a SWRC of 50\% the plants do not respond to a borated fertilization, with an average availability of water (SWRC 70\%) the boron accumulation increase with the doses, but the root and shoot dry mass, number of pods per plant and grain yield increase to the doses doses of 0.7 to $1.0 \mathrm{mg} \mathrm{dm}^{-3}$. When soil water availability is high (SWRC 90\%), root and shoot dry mass, boron accumulation in the plant and number of pods per plant increase up to the maximum tested.

Keywords - Glicyne max L., micronutrient, soil 


\section{INTRODUÇÃO}

O Brasil atualmente é um dos maiores países em produção e exportação de soja (Glycine max L.), sendo superado apenas pelos Estados Unidos. Nas últimas décadas tem se destacado como umas das culturas agrícolas com maior área plantada, de 33,109 milhões de hectares na safra 2015/16 (CONAB, 2016), contribuindo para a expansão da fronteira agrícola brasileira. O cultivo é viável devido o desenvolvimento de variedades adaptadas às várias regiões, tornando possível a sua produção em terras cultiváveis ociosas, com baixo nível de investimentos.

A soja aparece como uma cultura de grande relevância, pois seu aproveitamento vai desde a alimentação humana à alimentação animal nas rações, tornando uma excelente fonte de proteína com alto valor biológico, sendo matéria prima indispensável para a maioria das agroindústrias. (FERREIRA JUNIOR et al., 2010).

Dentre os fatores que afetam a produtividade da soja destacam-se a nutrição com macro e micronutrientes, associado aos fatores climáticos. A disponibilidade hídrica no solo contribuiu para a manutenção e conservação de fatores essenciais para o crescimento e desenvolvimento da planta. A água disponível nos solos está atrelada ao índice pluviométrico, distribuição das chuvas e características do solo (BEVILAQUA et al., 2002).

A água constitui aproximadamente $90 \%$ do peso total da planta de soja, participando em, praticamente, todos os processos fisiológicos e bioquímicos, desempenhando a função de solvente, transportando gases, minerais e outros solutos na planta (FARIAS et al., 2009).

Para um bom crescimento e desenvolvimento da cultura, além da água, é necessário um bom manejo nutricional, com macro e micronutrientes. Os últimos, apesar de serem exigidos em menores quantidades, são igualmente importantes para as plantas. Entre os micronutrientes, o boro se destaca por desempenhar na planta funções diretamente ligadas à produção. Malavolta (2006) salienta que ele incrementa o pegamento de flores e a granação em várias culturas, diminui a esterilidade masculina e o chochamento de grãos. Também atua como regulador enzimático e nos processos de estrutura e funcionamento das membranas, na formação da parede celular, síntese e transporte de carboidratos, síntese de proteínas, fixação de nitrogênio, fotossíntese e crescimento, além de proporcionar resistência às doenças (FERNANDES, 2006).
O boro na solução do solo encontra-se como ácido bórico, o qual chega até as raízes por fluxo de massa. A sua absorção ocorre de forma passiva em função do gradiente de concentração. $O$ transporte na planta pode ocorrer de maneira passiva pela difusão facilitada através da camada duplo- lipídica da membrana plasmática, por transportadores de alta afinidade induzido em baixa disponibilidade de boro, e a facilitação do transporte por NIP (nódulo de proteína intrínseca) proteínas de canal (TANAKA; FUJIWARA 2008).

A adubação é uma das maneiras de suprir a necessidade da planta e atenuar possíveis deficiências nutricionais de elementos praticamente imóveis na planta como o boro, sendo que o ácido bórico é a fonte mais utilizada. A adubação boratada, quando aplicada ao solo, pode ser perdida em partes por lixiviação (ROSOLEM; BÍSCARO, 2007), o que reforça uma estreita relação com a disponibilidade de água no solo.

Considerando que trabalhos realizados com respostas de boro na cultura da soja e a disponibilidade de água no solo são poucos e com resultados divergentes, torna-se nessessário a realização de novos estudos que possibilitem a utilização deste micronutriente de forma coerente nesta cultura.

O objetivo do trabalho foi avaliar a adubação com boro em função da disponibilidade de água no solo, sobre os componentes de produção, produtividade e acúmulo de boro na soja.

\section{MATERIAL E MÉTODOS}

O experimento foi conduzido em vasos sob casa de vegetação no Campus da Universidade Estadual de Goiás/UEG, situada no município de Ipameri-GO. Utilizou solo coletado na camada de 0 $0,20 \mathrm{~m}$ de um LATOSSOLO VERMELHO AMARELO Distrófico (SANTOS et al., 2013).

O delineamento experimental foi inteiramente casualizados (DIC), arranjado em esquema fatorial $3 \mathrm{x}$ 5 , com 4 repetições. O primeiro fator foi composto por três valores de capacidade de retenção de água do solo (CRA): 50, 70 e 90\% da capacidade máxima da CRA; e o segundo fator por cinco doses de boro: $(0 ; 0,5 ; 1,0$; 1,5 e 2,0 $\mathrm{mg} \mathrm{dm}^{-3}$ ) usando ácido bórico como fonte.

Para estimar a CRA foi coletada uma amostra de solo usado para preenchimento dos vasos, acondicionada em anel volumétrico medindo 4,5 x $4,5 \mathrm{~cm}$ com tecido perflex e fixado com ligas elásticas, para evitar perda de solo. A amostra foi umedecida por capilaridade durante 24 horas em recipiente com água 
até a altura de um terço do anel. Posteriormente, o anel foi retirado do recipiente com água, drenando o excesso, para determinar o peso úmido do solo, sendo esta condição considerada a máxima retenção de água no solo. Após a pesagem, a amostra foi seca em estufa na temperatura de $105^{\circ} \mathrm{C}$ até peso constante.

Fórmula de estimativa da CRA em (\%) pela equação abaixo.

$\mathrm{CRA}=\mathrm{SU}-\mathrm{SS} /(\mathrm{SS}-\mathrm{T}) * 100$

Onde:

CRA = Capacidade de Retenção de Água

$\mathrm{SU}=$ Solo úmido

$\mathrm{SS}=$ Solo Seco

$\mathrm{T}=$ Tara do conjunto (anel + elástico + pano)

Com os dados foram estabelecidas três condições de disponibilidade de água para as plantas: 50, 70 e 90\% da CRA. Esses valores de CRAs correspondem às tensões de 15,19 e $25 \mathrm{kPa}$, respectivamente, obtidas através da instalação de tensiômetro e leitura em tensímetro, em vaso com mesmo solo e volume utilizados no experimento. Os vasos foram corrigidos diariamente através de pesagens, sendo a diferença em gramas convertida em mililitros (ml) para restabelecer a condição de umidade do respectivo tratamento.

Uma amostra do solo foi submetida às análises químicas e físicas, conforme metodologias descritas em Silva (2009). Os resultados obtidos na análise de solo foram: $\mathrm{pH}\left(\mathrm{CaCl}_{2}\right)$ 5,1; $\mathrm{P}$ (Mehlich) 1,2 $\mathrm{mg} \mathrm{dm}{ }^{-3}$; M.O 9,0g dm${ }^{-3}$; K 17,0 $\mathrm{mg} \mathrm{dm}^{-3}$; Ca 0,8 $\mathrm{cmol}_{\mathrm{c}}$ $\mathrm{dm}^{-3} ; \mathrm{Mg} 0,3 \mathrm{cmol}_{\mathrm{c}} \mathrm{dm}^{-3} ; \mathrm{H}+\mathrm{Al} 2,2 \mathrm{cmol}_{\mathrm{c}} \mathrm{dm}^{-3} ; \mathrm{B}$ 0,19 $\mathrm{mg} \mathrm{dm}{ }^{-3}$; Cu 1,9 $\mathrm{mg} \mathrm{dm}^{-3}$; Fe 43,9 $\mathrm{mg} \mathrm{dm}^{-3}$; Mn 3,4 mg

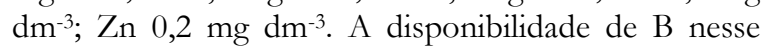
solo, segundo Ribeiro et al. (1999), é classificada como baixa. Foi aplicado calcário dolomítico visando elevar a saturação por bases para $60 \%, 30$ dias antes da semeadura. A adubação de base constou de $200 \mathrm{mg}$ $\mathrm{dm}^{-3}$ de $\mathrm{N}, 200 \mathrm{mg} \mathrm{dm}{ }^{-3} \mathrm{de} \mathrm{P}$ e $200 \mathrm{mg} \mathrm{dm}^{-3}$ de $\mathrm{K}$, utilizando como fonte ureia $(45 \%$ de $\mathrm{N})$, superfosfato triplo $\left(45 \%\right.$ de $\left.\mathrm{P}_{2} \mathrm{O}_{5}\right)$ e cloreto de potássio $(60 \%$ de $\left.\mathrm{K}_{2} \mathrm{O}\right)$ respectivamente.

A aplicação das doses de boro ocorreu antes da semeadura usando-se uma solução de $50 \mathrm{mg} \mathrm{L}^{-1} \mathrm{de}$ boro. A semeadura foi realizada em vasos de polietileno preenchidos com $5 \mathrm{dm}^{-3}$ de solo (com densidade de $0,902 \mathrm{~kg} \mathrm{dm}^{-3}$ de solo seco $105^{\circ} \mathrm{C}$ ), utilizando a variedade NS5909, de ciclo precoce, distribuindo-se oito sementes por vaso. No décimo segundo dia após a semeadura foi feito o desbaste deixando-se três plantas por vaso. A adubação básica com micronutrientes consistiu na aplicação de $3,66 \mathrm{mg}$ $\mathrm{Mn} ; 1,33 \mathrm{mg} \mathrm{Cu} ; 1,55 \mathrm{mg} \mathrm{Fe}$; 0,15 mg Mo e $4 \mathrm{mg}$ de $\mathrm{Zn}$ por $\mathrm{dm}^{3}$ de solo fornecidos na forma de $\mathrm{MnCl}_{2} .4 \mathrm{H}_{2} \mathrm{O}, \quad \mathrm{CuSO}_{4} .5 \mathrm{H}_{2} \mathrm{O}, \quad \mathrm{FeSO}_{4} .7 \mathrm{H}_{2} \mathrm{O}$, $\mathrm{NaMoO}_{4} \cdot 2 \mathrm{H}_{2} \mathrm{O}$ e $\mathrm{ZnSO}_{4} .7 \mathrm{H}_{2} \mathrm{O}$, conforme Novais et al. (1991).

O tratamento de sementes foi realizado com os seguintes produtos fitossanitários: fungicida MaximAdvance (acilalaninato $20 \mathrm{~g} \mathrm{~L}^{-1}$,tiabendazol 150 $\mathrm{g} \mathrm{L}^{-1}$, fludioxonil $\left.25 \mathrm{~g} \mathrm{~L}^{-1}\right)$, aplicando-se $100 \mathrm{ml}$ para cada $100 \mathrm{~kg}$ de sementes; inseticida Cruiser $\left(350 \mathrm{~g} \mathrm{~L}^{-1} \mathrm{de}\right.$ tiametoxan), na dose de $200 \mathrm{ml}$ para cada $100 \mathrm{~kg}$ de sementes; e inoculação com Bradyrbizobium japonicum,na dose de $250 \mathrm{~g}$ para cada $100 \mathrm{~kg}$ de sementes.

Os tratos culturais foram realizados de maneira preventiva para o controle de doenças e pragas. Utilizou-se fungicida à base de estrobilurina e triazol (Fox 0,4 L ha-1) na primeira aplicação no início do florescimento e após 18 dias da primeira aplicação, aplicou-se triazolintiona (Priori $0,3 \mathrm{~L} \mathrm{ha}^{-1}$ ). Para o controle de percevejos no enchimento dos grãos utilizou-se o inseticida do grupo químico neonicotinóide e piretróide (Connect 1,0 L ha-1). As pulverizações foram realizadas com bomba de pressão manual com volume de calda de 200 litros por hectare.

$\mathrm{Na}$ colheita foram avaliados os seguintes parâmetros: número de vagens/planta, número de grãos/vagem, massa fresca e seca da parte aérea e raiz, acúmulo de boro (teor de $\mathrm{B}$ x massa seca) na parte aérea, raiz e acúmulo total de boro, a massa de 100 grãos e a produtividade total, sendo a umidade dos grãos corrigida para $13 \%$.

As plantas colhidas foram secas em estufa à $60^{\circ} \mathrm{C}$ com ventilação forçada por $48 \mathrm{~h}$, e moídas posteriormente. Foi realizada a digestão seca em mufla e a determinação de boro estabelecida por espectrofotometria com azometina-H, segundo metodologia descrita em Silva (2009).

Os dados foram submetidos a análises de variância, ao teste de Scott-Knott à $5 \%$ de probabilidade, para comparação de médias e análise de regressão para doses.

\section{RESULTADOS E DISCUSSÃO}

As interações foram significativas entre doses de boro e capacidade de retenção de água (CRA), para as variáveis massa seca de parte aérea (MSPA) e raiz (MSR). Os efeitos da CRAs em cada uma das doses testadas são apresentados na Tabela 1. A CRA de 50\% teve a menor massa seca de parte aérea entre os níveis de água no solo, independente das doses de boro. Isso ocorreu provavelmente porque o boro é um elemento 
que chega até as superfícies das raízes principalmente através do fluxo de massa, que depende da água presente no solo (MALAVOLTA et al., 1997). Entre as CRAs $70 \%$ e $90 \%$ não ocorreram diferenças significativas para MSPA, exceto na dose de $2 \mathrm{mg} \mathrm{dm}^{-3}$ de $\mathrm{B}$, sendo a maior massa seca obtida pela CRA de $90 \%$ com 26,2 g planta $^{-1}$ seguida de 18,7 e 2,0 g planta $^{-1}$ nos tratamentos de $70 \%$ e $50 \%$ respectivamente.

Tabela 1. Massa seca parte aérea (MSPA) e massa seca de raiz (MSR) em função da capacidade de retenção de agua no solo (CRA) e doses de boro. UEG- Câmpus Ipameri, GO. 2017

\begin{tabular}{|c|c|c|c|}
\hline \multirow{3}{*}{$\begin{array}{c}\text { Doses B } \\
\left(\mathrm{mg} \mathrm{dm}^{-3}\right)\end{array}$} & \multicolumn{3}{|c|}{$\overline{\text { CRA }}$} \\
\hline & $50 \%$ & $70 \%$ & $90 \%$ \\
\hline & \multicolumn{3}{|c|}{ MSPA $\left(\right.$ g planta $\left.^{-1}\right)$} \\
\hline 0 & $2,0 \mathrm{~b}$ & $18,2 \mathrm{a}$ & $20,2 \mathrm{a}$ \\
\hline 0,5 & $1,5 \mathrm{~b}$ & $20,0 \mathrm{a}$ & $21,7 \mathrm{a}$ \\
\hline 1,0 & $1,5 \mathrm{~b}$ & $21,2 \mathrm{a}$ & $23,2 \mathrm{a}$ \\
\hline 1,5 & $2,2 \mathrm{~b}$ & $20,0 \mathrm{a}$ & $24,5 \mathrm{a}$ \\
\hline 2,0 & $2,0 \mathrm{c}$ & $18,7 \mathrm{~b}$ & $26,2 \mathrm{a}$ \\
\hline \multirow[t]{2}{*}{ C.V. } & & $13 \%$ & \\
\hline & \multicolumn{3}{|c|}{ MSR (g planta $\left.{ }^{-1}\right)$} \\
\hline 0 & $1,5 \mathrm{c}$ & $5,0 \mathrm{~b}$ & $10,5 \mathrm{a}$ \\
\hline 0,5 & $2,0 \mathrm{c}$ & $8,7 \mathrm{~b}$ & $11,7 \mathrm{a}$ \\
\hline 1,0 & $1,0 \mathrm{c}$ & $7,7 \mathrm{~b}$ & $14,0 \mathrm{a}$ \\
\hline 1,5 & $1,5 \mathrm{c}$ & $7,5 \mathrm{~b}$ & $13,7 \mathrm{a}$ \\
\hline 2,0 & $2,2 \mathrm{c}$ & $6,7 \mathrm{~b}$ & $15,0 \mathrm{a}$ \\
\hline C.V. & & $25 \%$ & \\
\hline
\end{tabular}

C.V.: coeficiente de variação; médias seguidas pela mesma letra, na linha, não se diferem entre si pelo te ste de Scott Knott a $5 \%$ de probabilidade.

Os níveis de CRA no solo influenciaram a massa seca de raiz. Observou-se redução na MSR entre os três níveis de água; a CRA de $50 \%$ foi a que produziu menor quantidade de MSR, diferindo da CRA $70 \%$ que foi superior na produção de MSR, e a CRA $90 \%$ apresenta valor mais elevado para MSR. As condições de umidade do solo é um dos principais fatores relacionado ao bom desenvolvimento da planta e sua produção. Sendo assim, os dados obtidos neste trabalho comprovam que a disponibilidade de água interfere nos valores de MSR. Resultados que diferem dos encontrados por Trautmann et al. (2014), que não encontraram diferença entre os níveis de tensões de água no $\operatorname{solo}(0,01 ; 0,03$; e $0,10 \mathrm{MPa})$, doses e fontes de boro, na matéria seca de caule, folhas e massa seca total em plantas de soja.
As respostas das plantas às doses de $\mathrm{B}$ também foram variáveis com a disponibilidade de água do solo. Os ajustes para doses não foram significativos na CRA 50\% para variáveis MSPA e MSR.

Com a CRA $70 \%$, houve ajuste polinomial para a MSPA e MSR, obtendo-se valor máximo 20,8 e 7,75 $\mathrm{g}_{\text {planta }}{ }^{-1}$, respectivamente, com a dose de $1 \mathrm{mg}$ $\mathrm{dm}^{-3}$ de boro (Figuras $1 \mathrm{~A}$ e $1 \mathrm{~B}$ ).
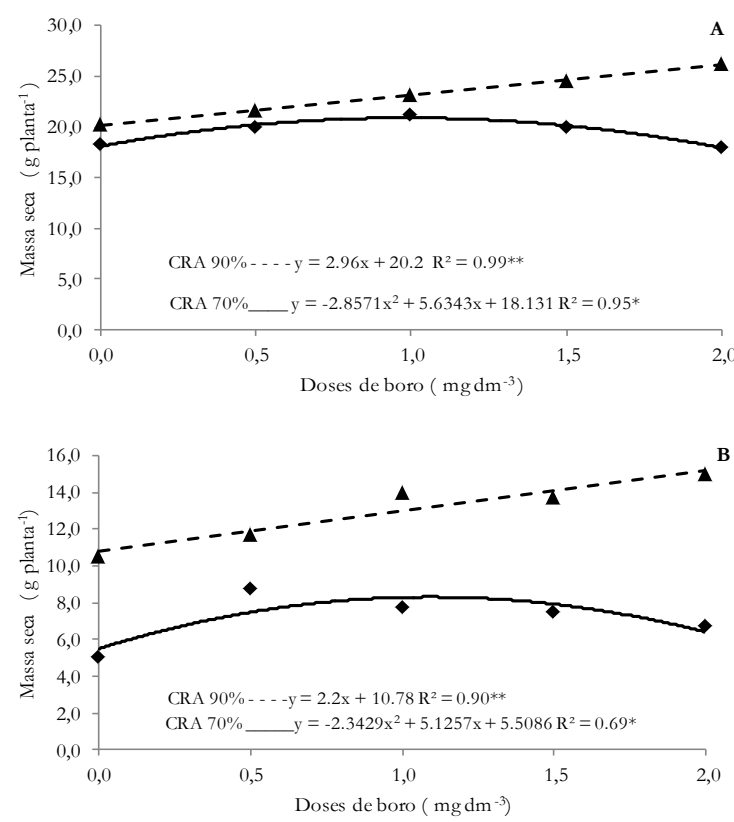

Figura 1. Massa seca de parte aérea e massa seca de raiz em função das doses de boro aplicadas e capacidade de retenção de água no solo. (A) MSPA 70\% e 90\% (B) MSR 70\% e MSR 90\%. * e ** = significativo a 5 e $1 \%$ de probabilidade, respectivamente.UEG, Ipameri-GO, 2017.

$\mathrm{Na}$ CRA de $90 \%$ o ajuste foi linear para MSPA 26,2 g planta $^{-1}$ e de $15 \mathrm{~g} \mathrm{planta}^{-1}$ de MSR até a dose de $2,0 \mathrm{mg} \mathrm{dm}^{-3} \mathrm{de}$ boro (Figuras $1 \mathrm{~A}$ e $1 \mathrm{~B}$ ). Com disponibilidade de água de $70 \%$ da CRA, a dose de 1 $\mathrm{mg} \mathrm{dm}^{-3}$ de boro foi a que melhor favoreceu a produção de MSPA e MSR, enquanto que com $90 \%$, foi a dose $2 \mathrm{mg} \mathrm{dm}^{-3}$.

Esses resultados indicam que o aumento das doses não foi eficiente para compensar uma possível redução na absorção do Boro em solos mais secos. Ou que as maiores produções de MSPA e MSR aumentaram a demanda por boro. Resultados que corroboram com os de Castro et al. (2006), que estudando o efeito do estresse hídrico no girassol também verificaram que as maiores produtividades de 
matéria seca foram obtidas nos tratamentos com maior disponibilidade de água.

A disponibilidade de água no solo e as doses de boro também apresentaram interações significativas para acúmulo de boro na parte aérea (ACPA), na raiz (ACR) e total (ACT). Os valores obtidos para essas três variáveis na CRA de 50\% foram inferiores aos de 70\% e $90 \%$ em todas as doses (Tabela 2). Isso aconteceu provavelmente porque o movimento do boro no solo é predominantemente via fluxo de massa, depende da água presente no solo (MATTIELLO et al., 2009). O tratamento $50 \%$ de CRA não foi suficiente para absorção e transporte do elemento até a parte aérea da planta de soja, talvez o que justifique o menor acúmulo de boro para este tratamento. Paula et al. (2012) ressaltam que plantas com deficiência hídrica tendem a

Tabela 2. Acúmulo de boro na parte aérea (ACPA), raiz (ACR) e acúmulo total (ACT) em função da capacidade de retenção de água no solo (CRA) e doses de boro aplicadas. UEG - Câmpus Ipameri, GO. 2017

\begin{tabular}{|c|c|c|c|}
\hline \multirow{3}{*}{$\begin{array}{c}\text { Doses B } \\
\left(\mathrm{mg} \mathrm{dm}^{-3}\right)\end{array}$} & \multicolumn{3}{|c|}{ CRA } \\
\hline & $50 \%$ & $70 \%$ & $90 \%$ \\
\hline & \multicolumn{3}{|c|}{ Boro na parte aérea $\left(\mathrm{mg} \text { planta }^{-1}\right)_{-}$} \\
\hline 0 & $0,09 \mathrm{c}$ & $0,36 \mathrm{~b}$ & $0,95 \mathrm{a}$ \\
\hline 0,5 & $0,08 \mathrm{c}$ & $0,56 \mathrm{~b}$ & $0,90 \mathrm{a}$ \\
\hline 1,0 & $0,10 \mathrm{~b}$ & $0,75 \mathrm{a}$ & $0,77 \mathrm{a}$ \\
\hline 1,5 & $0,11 \mathrm{~b}$ & $0,92 \mathrm{a}$ & $1,11 \mathrm{a}$ \\
\hline 2,0 & $0,07 \mathrm{~b}$ & $0,94 \mathrm{a}$ & $2,60 \mathrm{a}$ \\
\hline \multirow[t]{2}{*}{ C.V. } & \multicolumn{3}{|c|}{$33 \%$} \\
\hline & \multicolumn{3}{|c|}{ _Boro na Raiz (mg planta ${ }^{1}$ ) } \\
\hline 0 & $0,05 \mathrm{~b}$ & $0,19 \mathrm{a}$ & $0,18 \mathrm{a}$ \\
\hline 0,5 & $0,05 \mathrm{~b}$ & $0,17 \mathrm{a}$ & $0,21 \mathrm{a}$ \\
\hline 1,0 & $0,04 \mathrm{~b}$ & $0,20 \mathrm{a}$ & $0,20 \mathrm{a}$ \\
\hline 1,5 & $0,04 \mathrm{c}$ & $0,19 \mathrm{~b}$ & $0,26 \mathrm{a}$ \\
\hline 2,0 & $0,06 \mathrm{c}$ & $0,16 \mathrm{~b}$ & $0,28 \mathrm{a}$ \\
\hline \multirow[t]{2}{*}{ C.V. } & \multicolumn{3}{|c|}{$18 \%$} \\
\hline & \multicolumn{3}{|c|}{ Boro total (mg planta $\left.{ }^{1}\right)$} \\
\hline 0 & $0,14 \mathrm{c}$ & $0,55 \mathrm{~b}$ & $1,13 \mathrm{a}$ \\
\hline 0,5 & $0,13 \mathrm{c}$ & $0,74 \mathrm{~b}$ & $1,11 \mathrm{a}$ \\
\hline 1,0 & $0,13 \mathrm{~b}$ & $0,97 \mathrm{a}$ & $0,95 \mathrm{a}$ \\
\hline 1,5 & $0,15 \mathrm{~b}$ & $1,12 \mathrm{a}$ & $1,37 \mathrm{a}$ \\
\hline 2,0 & $0,13 \mathrm{c}$ & $1,10 \mathrm{a}$ & $2,90 \mathrm{a}$ \\
\hline C.V. & \multicolumn{3}{|c|}{$27 \%$} \\
\hline
\end{tabular}

C.V.: coeficiente de variação; médias seguidas pela mesma letra, na linha, não se diferem entre si pelo teste de Scott Knott a $5 \%$ de probabilidade.

com consequente redução na condutância estomática, na taxa fotossintética e na transpiração e, fechar os estômatos, consequentemente a redução na absorção de água. Segundo Barber (1995),o transporte do boro no solo até as raízes das plantas depende principalmente da absorção de água pela planta.

$\mathrm{Na}$ CRA de $70 \%$, os valores de ACPA nas doses 0 e $0,5 \mathrm{mg} \mathrm{dm}^{-3}$ foram inferiores em relação aos da CRA de $90 \%$. A quantidade de água do tratamento da CRA de $90 \%$ fez com que mesmo com a menor quantidade de boro no solo houvesse maior absorção através da solução do solo pelas raízes da soja e acumulado na parte aérea. Dechen et al. (1991) relatam que a parte aérea das plantas contém maior concentração de boro.

Os valores de ACR nas doses de 1,5 e 2,0 mg $\mathrm{dm}^{-3}$ de boro na CRA de $70 \%$ foram inferiores aos encontrados na CRA de $90 \%$. Esse maior acúmulo de boro na raiz na CRA de $90 \%$ deve ter sido em decorrência da maior disponibilidade de água e maior produção de massa seca. Mattielo et al. (2009) ressaltam que o déficit hídrico possui capacidade de alterar o balanço dos mecanismos de transporte de boro no solo, principalmente nos solos pobres desse nutriente, reduzindo o fluxo de massa e o acúmulo na planta.

Entanto na CRA de $70 \%$ as doses de boro 0 e $0,5 \mathrm{mg} \mathrm{dm}^{-3}$ o ACT foram inferiores à CRA de $90 \%$. Como nas doses a partir de $1,0 \mathrm{mg} \mathrm{dm}^{-3}$ de $\mathrm{B}$ não foram observadas diferenças significativas no ACT, esses resultados indicam que existe uma certa seletividade à absorção nutriente, evitando absorção excessiva. O boro na solução do solo depende da água, a disponibilidade de boro geralmente diminui com a redução da umidade, fato este que não ocorreu no tratamento de $90 \%$ CRA. O fluxo de massa é o mecanismo que predomina para o transporte do boro até as raízes das plantas (MALAVOLTA et al., 1997). Assim a CRA de 90\% através do fluxo de massa, proporcionou maior absorção deste micronutriente pelas raízes, e consequentemente um maior acúmulo do boro total nas plantas.

Com a CRA de $50 \%$ os ajustes testados não foram significativos. Houve ajuste linear para o acúmulo de boro na parte aérea da planta, na CRA de $70 \%$, cujos valores estimados foram de 0,304 a 1,01 mg planta-1 com as doses de 0 a $2 \mathrm{mg} \mathrm{dm}^{-3}$ respectivamente (Figura 2A). Esse resultado demonstra que com a CRA $70 \%$, a dose $2 \mathrm{mg} \mathrm{dm}^{-3}$ não foi suficiente para atingir o valor máximo na parte aérea das plantas de soja. Rosolem et al. (2012), trabalhando com quatros cultivares de algodão obtiveram resultados semelhantes aos deste trabalho, sendo que as quatros cultivares apresentaram respostas lineares para o acúmulo de boro total nas plantas de algodoeiro. Os dados da CRA 
de $90 \%$ ajustaram de forma quadrática para o acúmulo de boro na parte aérea.

O maior acúmulo de boro na CRA de $90 \%$ também foi obtido com a dose de $2,0 \mathrm{mg} \mathrm{dm}^{-3}$ de boro no solo, que foi de 2,65 mg planta ${ }^{-1}$ (Figura 2A). Estudando soja, Rosolem et al. (2008) verificaram resposta quadrática nos teores de boro nas folhas de soja, até $7,5 \mathrm{~kg} \mathrm{ha}^{-1}$ de boro.
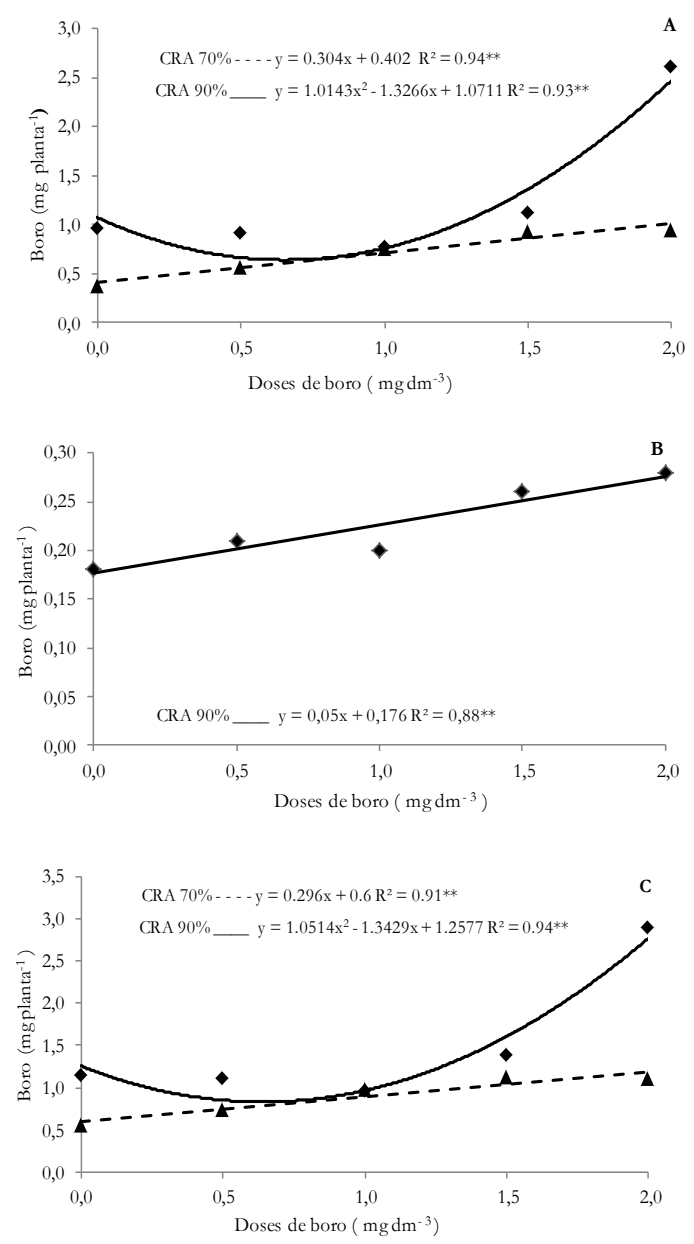

Figura 2. Acúmulo de boro na parte aérea de planta (ACPA), raiz (ACR) e acúmulo total de boro (ACT), em função de doses de boro e capacidade de retenção de água (CRA). (A) ACPA 70\% e 90\%,(B) ACR 90\%, (C) ACT 70\% e 90\%. * e ** = significativo a 5 e $1 \%$ de probabilidade, respectivamente. UEG, Ipameri, GO. 2017.

O acúmulo de boro está diretamente relacionado com os teores de boro, massa seca de planta e a disponibilidade de água presente no solo, uma vez que para quantificar o acúmulo usa-se a massa seca e o teor nos tecidos foliar, quanto maior a massa seca maior é o acumulo de boro. Para o acúmulo de boro na raiz apenas a CRA de $90 \%$ apresentou ajuste significativo, que aumentou de forma linear com as doses, verificou-se acúmulo $0,28 \mathrm{mg}$ planta- ${ }^{-1} \mathrm{com}$ a dose de $2 \mathrm{mg} \mathrm{dm}^{-3}$ de boro (Figura 2B). Na CRA de $90 \%$ as doses de boro não foram suficientes para atingir $\mathrm{O}$ valor máximo para o acúmulo de boro, mas os valores encontrados foram maiores que as CRAs de 50 e $70 \%$.

Pavinato et al. (2009), estudando a cultura do arroz em solução nutritiva com boro, ressaltam o acúmulo crescente de boro na cultivar Talento. Segundo Xavier (2014), doses crescentes de boro em porta enxerto de caramboleira não apresentou correlação com o acúmulo de boro nas raízes das plantas. O boro na solução do solo move-se até as raízes por meio do fluxo de massa, até que ocorra um equilíbrio entre as concentrações do nutriente nas raízes e na solução (DECHEN; NACHTIGALL, 2007).

O acúmulo de boro total na CRA de $70 \%$ ajustou de forma linear, aumentando com as doses de boro (Figura 2C). A CRA de 70\%, apesar de estar em um nível mediano de umidade entre os tratamentos de capacidade de retenção de água no solo, alcançou 1,1 $\mathrm{mg}$ de boro planta ${ }^{-1}$ na dose de $2 \mathrm{mg} \mathrm{dm}^{-3}$ de boro, diferentemente da massa seca de parte aérea e raiz. Em altas concentrações no solo, a absorção do boro é passiva, pelo processo de difusão facilitada na camada lipídica, bem como pelas proteínas de canais (TANAKA; FUJIWARA 2008) O acúmulo de boro está relacionado a massa seca. Pavinato et al. (2009) ressaltam que o total acumulado de boro por planta de arroz foi crescente com as doses aplicadas, assim aumentando o acúmulo de boro total.

$\mathrm{Na}$ CRA de $90 \%$ houve ajuste quadrático para o acúmulo total de boro na soja (Figura 2C). Nas doses de $0,0,5$ e $1,0 \mathrm{mg} \mathrm{dm}^{-3}$ o acúmulo de boro decresceu até a dose de $1 \mathrm{mg} \mathrm{dm}^{-3}$, sendo crescente a partir da dose de $1,5 \mathrm{mg} \mathrm{dm}^{-3}$ e alcançando acúmulo de $2,9 \mathrm{mg}$ planta $^{-1}$ na dose de $2,0 \mathrm{mg} \mathrm{dm}^{-3}$. As doses de $0,0,5$ e 1,5 $\mathrm{mg} \mathrm{dm}{ }^{-3}$ foram estáveis quanto ao acúmulo de boro, sendo as doses de 1,5 e $2,0 \mathrm{mg} \mathrm{dm}^{-3}$ superiores no acúmulo de boro na CRA de $90 \%$. Nessa CRA, o valor de ACT na dose 0 foi maior ou igual a qualquer dose nas CRAs inferiores. O que pode ter ocorrido porque, além dessa condição favorecer o fluxo de massa e a absorção pelas plantas, foi uma maior taxa de mineralização do $\mathrm{B}$ da matéria orgânica, que também é influenciada pela umidade, aumentando a disponibilidade do elemento no solo. Também a transpiração aumenta quando a disponibilidade de água está em níveis mais elevados, como é o caso da CRA 
$90 \%$, tendo como consequência o maior acúmulo de boro total na planta de soja. O acúmulo de boro em órgãos de plantas é determinado principalmente pela transpiração (PAVINATO et al., 2009). Entre os fatores ambientais não edáficos, a transpiração é a que mais influencia na absorção de boro. $\mathrm{O}$ aumento da transpiração promove o aumento na absorção de boro que é influenciada pela umidade relativa, temperatura e intensidade luminosa (HU; BROWN, 1997).

O número de vagens por planta apresentou interações significativas entre doses de boro e CRAs. A CRA de $50 \%$ foi inferior às de $70 \%$ e $90 \%$, sendo que na CRA de 70\% nas doses de 0, 0,5 e 1,0 $\mathrm{mg} \mathrm{dm}^{-3}$ foram iguais estatisticamente com a CRA de $90 \%$ para o número de vagem (Tabela 3). A maior disponibilidade de água com CRA de $90 \%$ proporcionou 32,0 vagens planta-1 ${ }^{-1}$ As doses de boro na CRA de $50 \%$ foram inferiores comparando com as mesmas doses CRA de $70 \%$ e $90 \%$, exceto as dose de 1,5 e $2,0 \mathrm{mg} \mathrm{dm}^{-3}$ na CRA de $70 \%$ que foram inferiores a CRA $90 \%$.

Tabela 3. Número de vagens e grãos por vagem em função da capacidade de retenção de água no solo (CRA) e doses de boro aplicadas. UEG- Câmpus Ipameri, GO. 2017

\begin{tabular}{|c|c|c|c|}
\hline \multirow{3}{*}{$\begin{array}{c}\text { DoseB } \\
\left(\mathrm{mg} \mathrm{dm}^{-3}\right)\end{array}$} & \multicolumn{3}{|c|}{ CRA } \\
\hline & $50 \%$ & $70 \%$ & $90 \%$ \\
\hline & \multicolumn{3}{|c|}{ Vagens/planta } \\
\hline 0 & $3,4 \mathrm{~b}$ & $17,6 \mathrm{a}$ & $22,2 \mathrm{a}$ \\
\hline 0,5 & $3,4 \mathrm{~b}$ & $18,6 \mathrm{a}$ & $22,0 \mathrm{a}$ \\
\hline 1,0 & $1,6 \mathrm{~b}$ & $19,2 \mathrm{a}$ & $23,7 \mathrm{a}$ \\
\hline 1,5 & $3,0 \mathrm{c}$ & $18,7 \mathrm{~b}$ & $32,0 \mathrm{a}$ \\
\hline 2,0 & $4,0 \mathrm{c}$ & $11,1 \mathrm{~b}$ & $25,2 \mathrm{a}$ \\
\hline \multirow[t]{2}{*}{ C.V. } & \multicolumn{3}{|c|}{$33 \%$} \\
\hline & \multicolumn{3}{|c|}{ _Grãos/Vagens_ } \\
\hline 0 & $1,5 \mathrm{a}$ & $1,7 \mathrm{a}$ & $1,8 \mathrm{a}$ \\
\hline 0,5 & $1,4 \mathrm{a}$ & $1,5 \mathrm{a}$ & $1,9 \mathrm{a}$ \\
\hline 1,0 & $1,4 \mathrm{a}$ & $1,5 \mathrm{a}$ & $1,9 \mathrm{a}$ \\
\hline 1,5 & $1,4 \mathrm{a}$ & $1,7 \mathrm{a}$ & $2,0 \mathrm{a}$ \\
\hline 2,0 & $1,5 \mathrm{a}$ & $1,8 \mathrm{a}$ & $2,1 \mathrm{a}$ \\
\hline C.V. & \multicolumn{3}{|c|}{$21 \%$} \\
\hline
\end{tabular}

C.V. : coeficiente de variação; médias seguidas pela mesma letra, na linha, não se diferem entre si pelo teste de Scott Knott a $5 \%$ de probabilidade.

A dose que melhor expressou o maior número de vagens foi a de $1,5 \mathrm{mg} \mathrm{dm}^{-3}$ na CRA de 90 $\%$ comparando com a CRA de 50 e $70 \%$, que atingiu 32,0 vagens planta ${ }^{-1}$. Castagnel e Silva (2009), avaliando a aplicação de boro via folha no feijoeiro, obtiveram aumento no número de vagens planta-1. $\mathrm{O}$ aumento do número de vagens, segundo Farinelli et al. (2006), ocorre devido o boro atuar no crescimento do tubo polínico e na produção de frutos e sementes.

Não houve ajuste significativo para o efeito de doses com o número vagens por planta na CRA de $50 \%$. O ajuste foi quadrático, com a dose de $0,72 \mathrm{mg}$ $\mathrm{dm}^{-3}$ obtendo-se o número máximo de 21,13 vagens planta $^{-1}$ na CRA de 70\% (Figura 3A).

A CRA de $90 \%$ apresentou ajuste linear para número de vagens, onde a dose de $2 \mathrm{mg} \mathrm{dm}^{-3}$ alcançou 26,99 vagens planta ${ }^{-1}$ (Figura 3A). Com maior disponibilidade de água neste tratamento, pode ter ocorrido efeito de diluição na concentração do boro no solo, fazendo com que a diluição permitisse um melhor aproveitamento pela planta de soja e consequentemente tendo efeito linear na produção de vagens planta ${ }^{-1}$.

Bevilaqua et al. (2002), testando aplicação foliar de Ca e B na cultura da soja em vários estádios, observaram aumento no número de vagens por planta, quando aplicados na fase de floração, na cv. BR16. Discordando dos resultados encontrados neste trabalho, Costa et al. (2014), trabalhando com aplicação de boro em três estádios na cultura do feijoeiro a campo, não encontraram diferenças significativas para o número de vagens por planta e número de grãos por vagem.

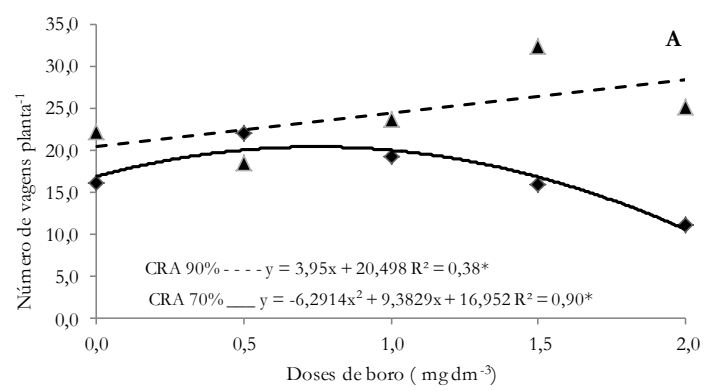

Figura 3. Número de vagens por planta em função de doses de boro aplicadas e capacidade de retenção de água (CRA). $70 \%$ e $90 \%$. * significativo a $5 \%$ de probabilidade.UEG, Ipameri, GO. 2017.

Para a massa de 100 grãos a CRA de $70 \%$ foi superior às outras duas CRAs, que, entretanto não diferiram entre si na dose 0 e de $2,0 \mathrm{mg} \mathrm{dm}^{-3}$ (Tabela 4). A dose de $0,5 \mathrm{mg} \mathrm{dm}^{-3}$ na CRA de $50 \%$ obteve maior massa de 100 grãos em comparação com a CRA de 70 e $90 \%$. As doses de 1,0 e $1,5 \mathrm{mg} \mathrm{dm}^{-3}$ de boro foram iguais para a CRA de 50, 70 e $90 \%$ exceto a dose de $1,5 \mathrm{mg} \mathrm{dm}^{-3}$ na CRA de 90\% que obteve 15,0 gramas sendo este valor inferior aos demais. A dose de $2,0 \mathrm{mg} \mathrm{dm}^{-3}$ de boro alcançou 23,8 gramas para o peso 
de 100 grãos na CRA de $70 \%$ superando a CRA de 50 e $90 \%$ que tiveram peso de 15,3 e 18,7 gramas para o peso de 100 grãos respectivamente.

A produtividade de grãos na CRA de 50\% variou entre 1,0 e $1,2 \mathrm{~g}_{\text {planta }}{ }^{-1}$, valores estes que estão abaixo das CRAs de 70 e $90 \%$. A CRA de $70 \%$ ficou entre 4,5 e 7,0 $\mathrm{g} \mathrm{planta}^{-1}$, e a de $90 \%$ a produtividade de grãos variou de 5,7 a $7,7 \mathrm{~g}$ planta $^{-1}$. Os valores encontrados na CRA de 70 e $90 \%$ foram superiores aos de $50 \%$. Isto pode ser explicado devido ao fato que os tratamentos de 70 e $90 \%$ possuem maior disponibilidade de água no solo, fazendo com que a planta não sofresse estresse hídrico e tendo a quantidade de água necessária para suas funções metabólicas e não comprometendo a produção de grãos.

Bevilaqua et al. (2002), aplicando cálcio e boro foliar no feijoeiro, encontraram aumento no peso de grãos por planta de feijão, quando aplicados na fase de floração. Seidel e Basso (2012) verificaram que as aplicações de adubo foliar a base de cálcio e boro na dose de $3 \mathrm{~L} \mathrm{ha}^{-1}$, independente do estádio de desenvolvimento (R1, R2, R3 e R4), não influenciaram os componentes de produção e produtividade da soja. A CRA de 50\% apresentou ajuste quadrático para a variável massa de 100 grãos, sendo a dose de $1 \mathrm{mg} \mathrm{dm}^{-3}$

Tabela 4. Massa de 100 grãos e produtividade de grãos por planta em função da capacidade de retenção de água no solo (CRA) e doses de boro aplicadas. UEGCâmpus Ipameri, GO. 2017.

\begin{tabular}{|c|c|c|c|}
\hline \multirow{3}{*}{$\begin{array}{c}\text { Doses B } \\
\left(\mathrm{mg} \mathrm{dm}^{-3}\right)\end{array}$} & \multicolumn{3}{|c|}{$\overline{\mathrm{CRA}}$} \\
\hline & $50 \%$ & $70 \%$ & $90 \%$ \\
\hline & \multicolumn{3}{|c|}{ Massa de100 grãos (g) } \\
\hline 0 & $11,0 \mathrm{~b}$ & $17,5 \mathrm{a}$ & $14,0 \mathrm{~b}$ \\
\hline 0,5 & $27,8 \mathrm{a}$ & $22,3 \mathrm{~b}$ & $16,8 \mathrm{~b}$ \\
\hline 1,0 & $23,6 \mathrm{a}$ & $18,8 \mathrm{a}$ & $18,1 \mathrm{a}$ \\
\hline 1,5 & $26,5 \mathrm{a}$ & $30,3 \mathrm{a}$ & $15,0 \mathrm{~b}$ \\
\hline 2,0 & $15,3 \mathrm{~b}$ & $23,8 \mathrm{a}$ & $18,7 \mathrm{~b}$ \\
\hline \multirow[t]{2}{*}{ C.V. } & \multicolumn{3}{|c|}{$20 \%$} \\
\hline & \multicolumn{3}{|c|}{ __Produtividade de grãos (g planta ${ }^{-1}{ }_{-}$} \\
\hline 0 & $1,0 \mathrm{~b}$ & $4,5 \mathrm{a}$ & $5,7 \mathrm{a}$ \\
\hline 0,5 & $1,0 \mathrm{~b}$ & $7,0 \mathrm{a}$ & $6,2 \mathrm{a}$ \\
\hline 1,0 & $1,0 \mathrm{~b}$ & $7,0 \mathrm{a}$ & $6,0 \mathrm{a}$ \\
\hline 1,5 & $1,0 \mathrm{~b}$ & $6,2 \mathrm{a}$ & $7,7 \mathrm{a}$ \\
\hline 2,0 & $1,2 \mathrm{~b}$ & $4,2 \mathrm{a}$ & $6,5 \mathrm{a}$ \\
\hline C.V. & \multicolumn{3}{|c|}{$46 \%$} \\
\hline
\end{tabular}

de boro atingiu o valor máximo de 27,6 gramas (Figura 4 A). Silva et al. (2006), na cultura do feijoeiro, não encontraram diferença entre os tratamentos de boro, tendo média de 23 gramas para a massa de 100 grãos. Estudo realizado com soja e aplicação foliar com produto contendo $10 \%$ cálcio e $0,5 \%$ de boro na dose de $3 \mathrm{~L} \mathrm{ha}^{-1}$ nos estádios R2, R3 e R4 não diferiram estatisticamente para o peso de 1000 grãos, possivelmente pela quantidade adequada no solo e boa disponibilidade hídrica no decorrer do desenvolvimento da cultura (SEIDEL; BASSO, 2012).

As doses de boro aumentaram linearmente a massa de 100 grãos na CRA de 70\% (Figura 4A). Souza et al. (2008), trabalhando com aplicação foliar no estádio reprodutivo em quatro variedades de soja, verificaram menor massa de sementes quando a aplicação foi realizada no estádio R1 e maior massa de sementes para o estádio R3, indicando que a aplicação em R3 proporcionou maior acúmulo de massa seca,ressalva a boa disponibilidade hídrica durante a condução da cultura. Aplicando $10 \mathrm{~kg} \mathrm{ha}^{-1} \mathrm{em}$ diferentes formas na cultura da soja, Raimundi et al. (2013) verificaram que quando realizado a aplicação
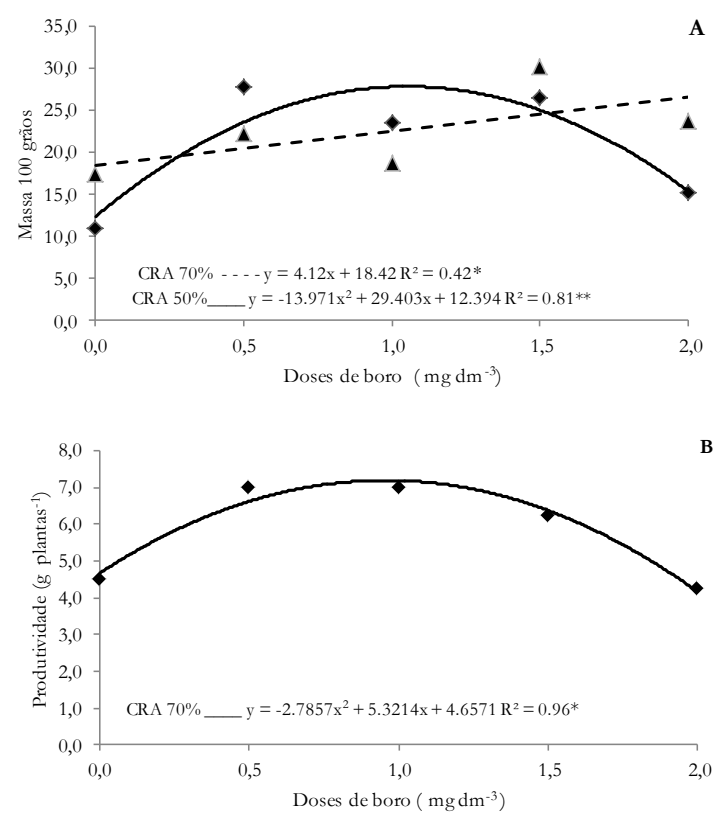

Figura 4. Massa de 100 grãos e produtividade por planta em função de doses de boro e capacidade de retenção de água (CRA). (A) Massa de 100 grãos 50\% e $70 \%$ da CRA; (B) Produtividade de grãos na CRA de 70\%.* e ** = significativo a 5 e $1 \%$ de probabilidade, respectivamente.UEG, Ipameri, GO. 2017. 
base combinada com lanço, obtiveram melhor resultado para o peso de 1000 de grãos, na média 153 gramas.

As doses de boro não influenciaram a produtividade de grãos nas CRAs de 50 e de $90 \%$. Ajuste quadrático foi encontrado para a CRA de 70\%, sendo a dose de $1 \mathrm{mg} \mathrm{dm}^{-3}$ a melhor para esta variável, atingindo 7 gramas planta ${ }^{-1}$ (Figura 4B). A disponibilidade de água para esta variável no tratamento de CRA de 70\% não foi fator que limitou o boro expressar a melhor dose para a produtividade planta $^{-1}$. Segundo Reis et al. (2008), trabalhando com doses e épocas de aplicação de boro no feijoeiro, não há diferença significativa para a produtividade, obtendo média de 3.587 e $3.710 \mathrm{~kg} \mathrm{ha}^{-1}$ para aplicação foliar e em cobertura respectivamente. De acordo com Kappes et al. (2008), as doses e épocas de aplicação de boro não influenciaram a produtividade da cultura da soja.

\section{CONCLUSÕES}

Com a baixa disponibilidade de água no solo (CRA 50\%), as plantas não respondem a adubação com boro.

No solo, com média disponibilidade de água (CRA 70\%), o acúmulo de boro na parte aérea e total aumentou de maneira linear até $2,0 \mathrm{mg} \mathrm{dm}^{-3}$, mas doses de 0,7 a $1,0 \mathrm{mg} \mathrm{dm}^{-3}$ proporcionam melhores resultados em termos de massa seca de raiz, parte aérea, número de vagens por planta e produtividade de grãos.

Quando a disponibilidade de água no solo é alta (CRA 90\%), a massa seca de parte aérea e raiz, o acúmulo de boro na planta e número de vagens por planta aumentam até a dose máxima testada, de 2,0 mg $\mathrm{dm}^{-3}$.

\section{AGRADECIMENTOS}

À Universidade Estadual de Goiás pela bolsa de incentivo ao pesquisador (PROBIP/PrP 009/2016) concedida ao último autor deste trabalho.

\section{REFERÊNCIAS}

BARBER, S.A. Soil nutrient bioavailability: A mechanistic approach. 2. ed. New York, John Wiley\& Sons, p. 330338, 1995.

BEVILAQUA, G. A. P.; FILHO, P. M. S.; POSSENTI, J. C. Aplicação foliar de cálcio e boro e componentes de rendimento e qualidade de sementes de soja. Ciência Rural, v.32, n.1, p. 31-34, 2002.
CASTAGNEL, J.; SILVA, T. R. B. Adubação foliar de boro na cultura do feijão. Cultivando o saber, v.2, n.3, p.716, 2009.

CASTRO, C. D., MOREIRA, A., OLIVEIRA, R. F. D., DCHEN, A. R..Boron and water stress on yield of sunflower. Ciência e Agrotecnologia, v. 30, n. 2, p. 214-220, 2006.

CONAB - Companhia Nacional de Abastecimento. Acompanbamento de safra brasileira: Grãos, Quinto Levantamento. Fevereiro/2016. Disponível em: < www.conab.gov.br/OlalaCMS/uploads/arquivos /16_02_04_11_21_34_boletim_graos_fevereiro_2016_ ok.pdf>. Acesso em: 30 jun. 2016.

COSTA, L.F.S.; CUNHA, A.H.N.; FERREIRA, E.M.; BRASIL, E.P.F.; FERREIRA, E.P.B. Aplicação de boro em feijoeiro e aspectos microbiológicos do solo. Revista Mirante, v. 7, n. 2, p.157-167, 2014.

DECHEN, A. R.; NACHTIGALL, G. R. Elementos requeridos à nutrição de plantas. In: NOVAIS, R. F.; ALVAREZ, V.; BARROS, N. F.; FONTES, R. L. F.; CANTARUTTI, R. B.; NEVES, J. C. L. (Ed.). Fertilidade do solo. Viçosa: Sociedade Brasileira de Ciência do Solo, 2007, p. 91-132.

DECHEN, A.R.; HAAG, H. P; CARNELLO, Q. A. C. Mecanismos de absorção e de translocação de micronutrientes. In: FERREIRA, M.E.; CRUZ, M.C.P. Micronutrientes na agricultura. Piracicaba: Instituto de Potassa e Fosfato, 1991, p. 79-130.

FARIAS, J. R. B.; NEUMAIER, N.; NEPOMUCENO, A. L. Soja. In: MONTEIRO, J. E. B. A. Agrometeorologia dos Cultivos: o fator meteorológico na produção agrícola. 1. ed. Brasília: INMET, 2009, p.263-277.

FARINELLI, R.: PENARIOL, F.G.: SOUZA, F.S.: PIEDADE, A.R.: LEMOS, L.B.: Características agronômicas e qualidade fisiológica de sementes de cultivares de feijão adubados via foliar com cálcio e boro. Revista Científica, v.34. n.1, p.59-65, 2006.

FERNANDES, M. S. Nutrição Mineral de Plantas. Viçosa, MG: Sociedade Brasileira de Ciência do solo, 432 p, 2006.

FERREIRA JUNIOR, J. A.; ESPINDOLA, S. M. C. G.; GONÇALVES, D. A. R.; LOPES, E. W. Avaliação de genótipos de Soja em diferentes épocas de plantio e densidade de semeadura no município de Uberaba MG. Fazu em Revista, n. 07, p.13-21, 2010. 
HU H.; BROWN P.H. Absorption of boron by plant roots. Plant and Soil, v.193, p.49-58, 1997.

KAPPES, C.; GOLO, A. L.; CARVALHO, M. A. C. Doses e épocas de aplicação foliar de boro nas características agronômicas e na qualidade de sementes de soja. Scientia Agraria, v. 9, n. 3, p. 291-297, 2008.

MALAVOLTA, E.; VITTI, G.C.; OLIVEIRA, S.A. Avaliação do estado nutricional das plantas: Princípios e aplicações. 2. ed. Piracicaba, Potafós, 1997, 319 p.

MALAVOLTA, E. Manual de nutrição mineral de plantas. São Paulo: Agronômica Ceres, 2006, 638 p.

MATTIELLO, E.M.; RUIZ, H.A.; SILVA, I.R.; BARROS, N.F.; NEVES, J.C.L. \& BEHLING, M. Transporte de boro no solo e sua absorção por eucalipto. Revista Brasileira de Ciência do Solo, v.33, p. 1281-1290, 2009.

NOVAIS, R.F.; NEVES, J.C.L.; BARRO, N.F. Ensaio em ambiente controlado. In: OLIVEIRA, A. J.; GARRIDO, W.E.; ARAÚJO, J.D.; LOURENÇO, S. Método de pesquisa em fertilidade do solo. Brasília: EMBRAPA-SEA, p. 189-253, 1991.

PAULA, R. C.; PAULA, N. F.; MARINO, C. L. Breeding perennial species for abiotic stress. In: FRISTCHE-NETO, R.; BORÉM, A. (Eds.) Plant breeding for abiotic stress tolerance.Berlin: Springer-Verlag, $\mathrm{p}$. 157-172, 2012.

PAVINATO, P.S.; AGUIAR, A.; CASTRO, G.S.A.; CRUSCIOL, C.A.C. Boro em arroz de terras altas cultivado em solução nutritiva. Bragantia, v. 68, n.3, p. 743-751, 2009.

RAIMUNDI, D. L.; MOREIRA, G. C.; TURRI, L. T. Modos de aplicação de boro na cultura da soja. Cultivando o Saber, v. 6, n. 2, p.112-121, 2013.

REIS, C. J.; SORATTO, R. P.; BISCARO, G. A.; KULCZYNSKI, S. M.; FERNANDES, D. S. Doses e modos de aplicação de boro na produção e qualidade fisiológica de sementes de feijão em solo de cerrado. Agronômica Ceres, v. 55, n. 4, p. 258-264, 2008.

RIBEIRO, A. C.; GUIMARÃES, P. T. G.; ALVAREZ, V. V. H. Recomendações para o uso de corretivos e fertilizantes em Minas Gerais: $5^{a}$ aproximação. Viçosa: Comissão de Fertilidade do solo do Estado de Minas Gerais. 1999. $360 \mathrm{p}$.
ROSOLEM, C. A.; DEUS, A. C. F.; MARTINS, P. O.; LÉLES, E. P. Acúmulo e distribuição de boro em cultivares de algodão. Revista Brasileira de Ciência do Solo. v. 36, p. 1231-1238, 2012.

ROSOLEM, C.A.; BÍSCARO, T. Adsorção e lixiviação de boro em Latossolo Vermelho-Amarelo. Pesquisa Agropecuária Brasileira, v. 42, p.1473-1478, 2007.

ROSOLEM, C. A.; ZANCANARO, L.; BÍSCARO, T. Boro disponível e resposta da soja em Latossolo Vermelho-Amarelo. Revista Brasileira de Ciência do Solo, v. 32, p. 2375-2383, 2008.

SANTOS, H. G.; JACOMINE, P. K. T.; ANJOS, L. H. C.; OLIVEIRA, V. A. V. LUMBRERAS, J. F. COELHO, M.; ALMEIDA, J. A.; CUNHA, T. J. F.; OLIVEIRA, J. B. Sistema Brasileiro de Classificação de Solos. 3 ed. rev. ampl. - Brasília, DF: Embrapa, 2013, $353 \mathrm{p}$.

SEIDEL, E. P.; BASSO, W. L. Adubação foliar a base de cálcio e boro no cultivo da soja (Glycine max). Scientia Agraria Paranaenis, v.11, n. 2, p 75-81, 2012.

SILVA, T. R. B; SORATTO, R. P. BISCARATO, T.; LEMOS, L. B. Aplicação foliar de boro e cálcio no feijoeiro. Cientifica, v. 34, n. 1, p. 46-52, 2006.

SILVA, F. C. Manual de análises químicas de solos, plantas e fertilizantes. 2. ed. Distrito Federal: Brasilia, 2009, 627p.

SOUZA, L. C. D.; SÁ, M. E.; CARVALHO, M. A. C.: SIMIDU, H. M. Produtividade de quatro cultivares de soja em função da aplicação de fertilizante mineral foliar a base de cálcio e boro. Revista de Biologia e Ciências da Terra, v. 8, n. 2, p. 37-44, 2008.

TANAKA M, FUJIWARA T. Physiological roles and transport mechanisms of boron: perspectives from plants. European Journal of Physiology, v. 456, p. 671-677, 2008.

TRAUTMANN, R. R.; LANA, M. C.; GUIMARÃES, V. F.; GONÇALVES JR, A. C.; STEINER, F. Potencial de água do solo e adubação com boro no crescimento e absorção do nutriente pela cultura da soja. Revista Brasileira de Ciência do Solo, v.38, n.1, p. 240251, 2014. 
XAVIER, C. V. Influência do boro no crescimento e acúmulo de nutrientes em porta-enxertos de caramboleira. 2014. 62p. Dissertação (Mestrado em Agronomia - Ciência do Solo) - Universidade Estadual Paulista, Faculdade de Ciências Agrárias e Veterinária, Universidade Estadual Paulista, Jaboticabal, 2014. 